International Journal of Medical Sciences

ISSN 1449-1907 www.medsci.org 2007 4(1):7-12

Research Paper

(C) Ivyspring International Publisher. All rights reserved

\title{
Low socio-economic status, smoking, mental stress and obesity predict obstructive symptoms in women, but only smoking also predicts subsequent experience of poor health
}

\author{
Jörgen Thorn 1, Cecilia Björkelund 1, Calle Bengtsson 1, Xinxin Guo 2, Lauren Lissner 1, and Valter Sundh \\ 1. Department of Public Health and Community Medicine/Primary Health Care, The Sahlgrenska Academy at Göteborg \\ University, SE-405 30 Göteborg, Sweden \\ 2. Neuropsychiatric Epidemiology Unit, Institute of Clinical Neurosciences, The Sahlgrenska Academy at Göteborg \\ University, SE-405 30 Göteborg, Sweden
}

Correspondence to: Jörgen Thorn, M.D. Department of Public Health and Community Medicine/Primary Health Care, The Sahlgrenska Academy at Göteborg University, Box 454, SE-405 30 Gothenburg, Sweden. Telephone +46 31773 6828, Fax +46 31778 1704, E-mail: jorgen.thorn@allmed.gu.se

\section{Received: 2006.09.04; Accepted: 2006.10.31; Published: 2006.11.03}

This study was conducted among female subjects to assess the possible association between selected risk factors and lung function as well as airway symptoms in a 32-year perspective. The Prospective Population Study of Women was initiated in 1968-1969 in Göteborg, Sweden (population about 450 000) with follow-ups in 1974-1975, 1980-1981, 1992-1993 and 2000-2001. Women born in 1930, representative of women of the same age in the general population in 1968, were selected. Initially, 372 participants were included in the cohort. In 2000-2001, 231 of these women $(73 \%)$, now 70 years old, underwent lung function tests. The main outcome measures were lung function values, airway symptoms and health outcome in 2000-2001 in relation to self-reported exposures in 1968-1969 including smoking status. Smoking in 1968-1969 was associated with self-reported chronic bronchitis, obstructive symptoms and poor health 32 years later as well as lower lung function values, compared to non-smokers. Obesity, low socio-economic status and self-reported mental stress in 1968-1969 were associated with obstructive symptoms 32 years later. There are only a few longitudinal studies concerning women's health problems in this field and epidemiological studies of lung function impairment in women and risk factors in a long-term perspective are scarce. The results of the study suggest that life-style factors such as mental stress, obesity and smoking among women are related to airway symptoms and also quality of life many years later.

Key words: Population study, female, smoking, socio-economic status, lung function

\section{Introduction}

Chronic obstructive pulmonary disease (COPD) is a growing health problem in women [1]. The major causative agent behind the disease is smoking, but there are few longitudinal studies concerning women's health problems in this field.

In 1968, a population study of women in Göteborg, Sweden, was initiated; engaging 1462 women aged 38-60, representative of the female population of Göteborg. Subsequently, four follow-up examinations have been performed, the latest in 2000-2001, i.e. 32 years after the initial examination. Lung function was measured as peak expiratory flow (PEF) by a peak flow meter in 1968-1969 and as PEF, vital capacity (VC) and forced expiratory volume in one second $\left(\mathrm{FEV}_{1}\right)$ at the 2000-2001 examination. A 12-year follow-up study on lung function has previously been presented from this population, in which reduced PEF increased the risk of cardiovascular disease (CVD) and death twelve years later, independent of the presence of risk factors for CVD [2].
In this paper, we present data concerning lung function, airway symptoms and health status in those women who were 38 years old at the initial examination and 70 years old at the 32-year follow up in 2000-2001.

As there are only a few longitudinal studies concerning women's health problems in this field and epidemiological studies of lung function impairment in women and risk factors in a long-term perspective are scarce we aimed to assess the possible association between selected risk factors among women and lung function, health status as well as airway symptoms in a 32-year perspective.

\section{Participants and methods}

\section{Participants}

The Prospective Population Study of Women in Gothenburg was initiated in 1968-1969 with an examination of 1462 (participation rate $90 \%$ ) women born in $1908(\mathrm{n}=81), 1914(\mathrm{n}=180), 1918(\mathrm{n}=398), 1922$ $(n=431)$ and $1930(n=372)$. The subjects were born on specific dates, which ensured that they were a 
representative cross-section of women in the community in the studied age strata. Re-examinations were performed in 1974-1975 ( $\mathrm{n}=1302), 1980-1981$ $(n=1154), 1992-1993(n=830)$ and 2000-2001 $(n=661)$, with participation rates (based on those who participated in 1968-1969 and were alive at the follow-up examinations) of $91 \%, 83 \%, 70 \%$ and $71 \%$, respectively.

The participation status of the original cohort (born in 1930) at the time of the 32-year follow-up is presented in Table 1. Details of the sampling procedure and participation rates for all five examinations are presented elsewhere [3-7]. In 1968-1969, 372 women (38 years old) underwent lung function examination with PEF as a part of the clinical examination. In 2000-2001, 231 of these women (73\%), now 70 years old, underwent lung function tests with PEF and spirometry.

Table 1. Background characteristics of the original cohort born in 1930 and the status of the subjects after 32 years

\begin{tabular}{|c|c|}
\hline Birth cohort 1930 & \\
\hline Age in 1968-1969 & 38 \\
\hline Age if alive in 2000-2001 & 70 \\
\hline Participants, 1968-1969 & 372 \\
\hline Available for study, 2000-2001 (alive June 15 2001) & 312 \\
\hline No spirometric examinations, 2000-2001 & 25 \\
\hline Clinical examination, 2000-2001 & 206 \\
\hline Non-participants, 2000-2001 & 81 \\
\hline Participation rate (\%) including home visits, 2000-2001 & 74 \\
\hline Smokers/Ex-smokers/Non-smokers, 1968-1969 & $85 / 23 / 99$ \\
\hline Smokers/Ex-smokers/Non-smokers, 2000-2001 & $33 / 70 / 104$ \\
\hline
\end{tabular}

All participants in the population study were physically examined and interviewed by physicians and research nurses. Information concerning education and socio-economic group was obtained by questionnaire, which was sent out beforehand. Data on smoking habits and pulmonary disease was obtained via an interview with a physician.

Socio-economic group in 1968-1969; The women reported their own occupations and, if they were married, their husbands' occupations. This information was transformed according to Carlson's standard occupations grouping system [8]:

- Group 1 = Large-scale employers and officials of high or intermediate rank was classified as the high socio-economic group;

- Groups 2 and 3 = Small-scale employers, officials of lower rank and foremen were combined into the "middle socio-economic group";

- Groups 4 and 5 = Skilled and unskilled workers were identified as belonging to the "low socio-economic group".

Smoking habits. "Current smokers" were identified as those who smoked $\geq 1$ cigarette per day. "Ex-smokers" were identified as those who had stopped smoking >1 year before the 1968-1969 examination.

Anthropometric measurements in 1968-1969; Body height and body weight were measured with the subjects wearing only briefs. Body mass index (BMI) was calculated by dividing body weight in $\mathrm{kg}$ by $\mathrm{m}^{2}$ of body height.

Mental stress in 1968-1969 was defined as one or several more than month-long periods of anxiety, agony, irritability, nervousness, tension, or insomnia due to worries regarding work, own health, family or conflicts at home or at work during the last five years.

Asthma, and colds, respectively, was defined as self-reported asthma and colds in 1968-1969.

Health status in 2000-2001 was defined as self-reported health. Subjects filled out a seven-point Likert-type scale anchored by "excellent, couldn't be better" and "very poor" for scores of 1 to 7 , with 1 representing the best. Respondents assessed current satisfaction with their health situation. The women were asked to complete the questionnaire at home before the examination.

Obstructive symptoms in 2000-2001 were defined as wheezing almost every day or more often.

Chronic bronchitis in 2000-2001 was defined as reported cough with phlegm at least three months per year, according to WHO standards.

Dyspnoea in 2000-2001 was defined as reported breathlessness when walking at one's own pace on level ground or when dressing.

Lung function tests; Experienced nurses performed lung function tests. A Wright peak-flow meter was used to measure PEF in 1968-1969 and a Miniwright peak-flow meter (Clement and Clarke) was used in 2000-2001 [2]. Subjects were asked to exhale with maximal effort from a position of maximal inspiration. Each subject performed the test three times and mean values were used as the final results in 1968-1969, and the highest value was used in 2000-2001. In 2000-2001, a Vitalograph Spirometer was used to measure VC and $\mathrm{FEV}_{1}$, with subjects in a sitting position and without using a nose clip. The results were expressed as absolute values in litres and as percentage of predicted values according to height, which were calculated in a linear regression model including $\mathrm{VC}, \mathrm{FEV}_{1}$ and $\mathrm{PEF}$ and individual heights. The other "standard" confounding factors for lung function measurements, gender and age, were not controlled for as the cohort only consisted of women of the same age. Subjects were asked to inhale to total lung capacity before beginning the forced expiration. Maximum effort was to be exerted throughout the expiration. Each subject performed the spirometry test three times and the highest value was used as the final result.

\section{Statistical analysis}

Parametric tests were used in the case of normal distribution and non-parametric tests for non-normal distributions ( $\chi^{2}$ or Fischer's exact test).

Logistic regression analyses were performed to compute odds ratios (OR) with 95\% confidence intervals (CI). For continuous variables, a linear regression model was applied. Stepwise multivariate regression models were applied to adjust for confounding of covariates. Tests for trends were performed by linear-by-linear rank correlation tests. The lung function data were treated as continuous 
variables and as quintiles. Differences were considered statistically significant at $\mathrm{p}<0.05$.

\section{Results}

Risk factors for airway symptoms and poor health in 2000-2001

Table 2 shows the OR with $95 \%$ CI for selected self-reported exposures in 1968-1969 in relation to airway symptoms and health outcome in 2000-2001. Among subjects who were smokers in 1968-1969, significantly higher OR were found for chronic bronchitis, obstructive symptoms, lower health score and lung function data in 2000-2001. Among those with low socio-economic status in 1968-1969, significantly higher OR was found for chronic bronchitis and obstructive symptoms. In addition, subjects reporting mental stress, $\mathrm{BMI}>28$ or a low PEF value in 1968-1969 had significantly higher OR for obstructive symptoms in 2000-2001. Low PEF values in 1968-1969 were associated with poor health 32 years later.

Risk factors for impaired lung function in 2000-2001

Table 3 shows lung function values in 2000-2001 in relation to selected self-reported exposures in 1968-1969. Lower PEF, $\mathrm{FEV}_{1}$ and $\mathrm{VC}$ values in 2000-2001 were related to asthma, smoking as well as previous smoking reported in 1968-1969. Smoking was also related to lower $\mathrm{FEV}_{1} / \mathrm{VC}$ values in 2000-2001. BMI > 25 in 1968-1969 was related to a higher $\mathrm{FEV}_{1} / \mathrm{VC}$ in $2000-2001$.

Table 2. Odds ratios (OR) with 95\% confidence intervals (CI) for selected self-reported exposures in 1968-1969, related to airway symptoms and health outcome in 2000-2001 (logistic regression model). Lung function data (in quintiles) 2000-2001 was also related to selected self-reported exposures in 1968-1969

\begin{tabular}{|c|c|c|c|c|}
\hline \multirow{3}{*}{ Exposure 1968-1969 } & OR $(95 \% \mathrm{CI})$ & OR $(95 \% \mathrm{CI})$ & OR $(95 \% \mathrm{CI})$ & OR $(95 \% \mathrm{CI})$ \\
\hline & & $\begin{array}{l}\text { Airway symptoms and health } \\
\text { outcome, 2000-2001 }\end{array}$ & & \\
\hline & Dyspnoea & Chronic bronchitis/cough & Obstructive symptoms & Poor health \\
\hline $\begin{array}{l}\text { Low socio-economic } \\
\text { group }\end{array}$ & $0.4(0.2-0.8)$ & $3.2(1.2-8.3)$ & $2.4(1.1-5.0)$ & $0.9(0.3-2.0)$ \\
\hline Ex-smoker & $0.3(0.1-0.8)$ & $0.8(0.1-7.1)$ & $1.8(0.5-6.5)$ & $0.3(0.03-2.6)$ \\
\hline Current smoker & $0.6(0.3-1.2)$ & $2.7(1.0-7.7)$ & $3.8(1.7-8.5)$ & $2.3(1.0-5.0)$ \\
\hline Mental stress & $0.5(0.2-1.2)$ & $1.2(0.4-3.8)$ & $2.2(1.0-5.1)$ & $1.6(0.6-4.0)$ \\
\hline $\mathrm{BMI}>25$ & $1.6(0.6-4.1)$ & $1.0(0.3-3.7)$ & $1.1(0.4-2.7)$ & $1.0(0.4-2.8)$ \\
\hline $\mathrm{BMI}>28$ & $0.6(0.1-2.6)$ & $1.5(0.1-8.8)$ & $4.1(1.1-16.0)$ & $2.2(0.5-9.2)$ \\
\hline Lowest quintile of PEF & $0.6(0.3-1.5)$ & $0.8(0.2-2.7)$ & $3.9(1.6-9.5)$ & $3.3(1.4-7.8)$ \\
\hline \multirow[t]{2}{*}{ Exposure 1968-1969 } & & Lung function, 2000-2001 & & \\
\hline & Lowest quintile of PEF (1/min) & Lowest quintile of $\mathrm{FEV}_{1}(\mathrm{l})$ & Lowest quintile of VC (l) & \\
\hline Ex-smoker & $0.6(0.1-3.1)$ & $1.1(0.2-5.9)$ & $1.3(0.3-5.5)$ & \\
\hline Current smoker & $2.5(1.2-5.4)$ & $4.6(1.9-11.2)$ & $2.7(1.2-6.5)$ & \\
\hline Lowest quintile of PEF & $6.9(2.8-16.9)$ & $6.4(2.6-15.6)$ & $7.9(3.2-19.5)$ & \\
\hline
\end{tabular}

BMI=Body Mass Index, l=litres

Table 3. Lung function values in 2000-2001 (PEF, $\mathrm{FEV}_{1}, \mathrm{VC}$ and $\mathrm{FEV}_{1} / \mathrm{VC}$ ) expressed as percentage of predicted value according to height, in relation to selected self-reported exposures in 1968-1969. The results are presented in percentages and standard deviations with p-values

\begin{tabular}{|c|c|c|c|c|c|c|}
\hline & PEF (\% (SD)) & p-value & $\mathrm{FEV}_{1}(\%(\mathrm{SD}))$ & p-value & $\mathrm{VC}(\%(\mathrm{SD}))$ & $\mathrm{p}$-value \\
\hline \multicolumn{7}{|l|}{ Exposure 1968-1969 } \\
\hline $\begin{array}{l}\text { Asthma/ } \\
\text { No asthma }\end{array}$ & $\begin{array}{l}71(29) / \\
102(23)\end{array}$ & 0.02 & $71(16) / 101(23)$ & 0.02 & $\begin{array}{l}74(12) / \\
101(21)\end{array}$ & 0.03 \\
\hline Cold/No cold & $\begin{array}{l}90(23) / \\
102(24)\end{array}$ & 0.02 & $94(22) / 101(23)$ & NS & $\begin{array}{l}95(20) / \\
101(22)\end{array}$ & NS \\
\hline $\begin{array}{l}\text { Ex-smoker/ } \\
\text { Never-smoker }\end{array}$ & $\begin{array}{l}97(25) / \\
106(22)\end{array}$ & 0.008 & $94(23) / 106(21)$ & 0.0008 & $\begin{array}{l}96(22) / \\
104(20)\end{array}$ & 0.01 \\
\hline \multirow[t]{2}{*}{$\begin{array}{l}\text { Current-smoker/ } \\
\text { Never-smoker }\end{array}$} & $\begin{array}{l}93(24) / \\
107(22)\end{array}$ & $<0.0001$ & $90(22) / 106(21)$ & $<0.0001$ & $\begin{array}{l}92(21) / \\
105(21)\end{array}$ & $<0.0001$ \\
\hline & $\mathrm{FEV}_{1} / \mathrm{VC}($ mean $(\mathrm{SD}))$ & $\mathrm{p}$-value & & & & \\
\hline \multicolumn{7}{|l|}{ Exposure 1968-1969 } \\
\hline Asthma/No asthma & - & - & & & & \\
\hline Cold/No cold & $\begin{array}{c}0.85(0.06) / \\
0.86(0.07)\end{array}$ & NS & & & & \\
\hline Ex-smoker/ Never-smoker & $\begin{array}{c}0.84(0.07) / \\
0.87(0.06)\end{array}$ & 0.002 & & & & \\
\hline $\begin{array}{l}\text { Current-smoker/ } \\
\text { Never-smoker }\end{array}$ & $\begin{array}{c}0.83(0.07) / \\
0.87(0.06)\end{array}$ & 0.0007 & & & & \\
\hline BMI $>25 /<25$ & $0.88(0.05) / 0.85(0.07)$ & 0.004 & & & & \\
\hline
\end{tabular}




\section{Multivariate regression analysis}

In stepwise multivariate logistic and linear regression models, current smoking and low socio-economic group in 1968-1969 were significantly associated with higher OR for chronic bronchitis (OR 3.3, 95\% CI 1.2-8.9 and OR 4.6, 95\% CI 1.6-13.3) and obstructive symptoms in 2000-2001 (OR 3.7, 95\% CI 1.8-8.0 and OR 3.2, 95\% CI 1.4-7.3). Current smoking in 1968-1969 was negatively related to PEF (regression coefficient, $\quad \mathrm{RC}=-9.6, \mathrm{p}<0.01), \mathrm{FEV}_{1} \quad(\mathrm{RC}=-15.2$, $\mathrm{p}<0.001), \mathrm{VC}(\mathrm{RC}=-12.8, \mathrm{p}<0.001)$ and $\mathrm{FEV}_{1} / \mathrm{VC}(\mathrm{RC}=$ $-0.04, \mathrm{p}<0.01$ ) in 2000-2001.

\section{Lung function data in relation to smoking status}

Table 4 shows lung function values in 2000-2001 in relation to smoking status. A significant trend was found between smoking status and lower lung function values.

Table 4. Lung function values in 2000-2001 (PEF, $\mathrm{FEV}_{1}, \mathrm{VC}$ and $\mathrm{FEV}_{1} / \mathrm{VC}$ ), expressed as percentage of predicted values according to height as well as absolute values in litres, in relation to smoking status. $\mathrm{N}=$ number of participants, $\mathrm{SD}=$ standard deviations

\begin{tabular}{|c|c|c|c|c|c|c|}
\hline & $\mathrm{N}$ & PEF (SD) & $\mathrm{N}$ & $\mathrm{FEV}_{1}(\mathrm{SD})$ & $\mathrm{VC}(\mathrm{SD})$ & $\mathrm{FEV}_{1} / \mathrm{VC}(\mathrm{SD})$ \\
\hline Never smokers & 98 & & 82 & & & \\
\hline$\%$ & & $106(23)$ & & $106(21)$ & $104(21)$ & $0.87(0.06)$ \\
\hline Litre & & 349 (77) & & $2.1(0.4)$ & $2.4(0.05)$ & - \\
\hline Stopped smoking $>15$ years ago & 41 & & 30 & & & \\
\hline$\%$ & & $100(23)$ & & $101(22)$ & $103(21)$ & $0.83(0.06)$ \\
\hline Litre & & $328(75)$ & & $2.0(0.4)$ & $2.3(0.5)$ & - \\
\hline Stopped smoking $<15$ years ago & 24 & & 18 & & & \\
\hline$\%$ & & $106(23)$ & & $93(20)$ & $94(20)$ & $0.84(0.08)$ \\
\hline Litre & & $346(73)$ & & $1.8(0.4)$ & $2.1(0.4)$ & - \\
\hline Current smokers 2001 & 34 & & 23 & & & \\
\hline$\%$ & & $85(19)$ & & $84(23)$ & $87(22)$ & $0.83(0.07)$ \\
\hline Litre & & $282(60)$ & & $1.7(0.4)$ & $2.0(0.5)$ & - \\
\hline$p$-values for trend & & $P<0.001$ & & $P<0.001$ & $P<0.001$ & $P=0.003$ \\
\hline
\end{tabular}

\section{Non-participant characteristics}

In order to understand whether participants in 2000-2001 were representative of the original cohort examined in 1968-1969 a comparison was made. Non-participants in 2000-2001 (see table 1) had significantly lower BMI (22.9 vs. 24.0) in 1968-1969 than participants but there were no significant differences between the groups concerning smoking status, education, civil status, mental stress, physical activity or PEF at the 1968-1969 examination.

\section{Discussion}

\section{Main finding of this study}

Smoking, low socio-economic status, mental stress, and obesity predicted obstructive symptoms in women and smoking alone also predicted subsequent experience of poor health in a 32-year perspective. Smoking seemed to have deleterious effects not only on the airways but also on quality of life in a long-term perspective.

In our study, smoking in 1968-1969 was related to reports of chronic bronchitis $>30$ years later. These results are in accordance with the results of the Copenhagen City Heart Study, in which approximately 3700 (2200 women and 1500 men) elderly participants (mean age 76) were enrolled. They were studied in 1976-1978 and again in 1991-1994. The prevalence of chronic bronchitis was $13 \%$ in women and $18.6 \%$ in men. This diagnosis was related to mortality from all kinds of respiratory diseases as well as to both previous and present smoking. The authors conclude that chronic bronchitis is a prevalent condition with important prognostic implications in an elderly population [9].

We found that self-reported asthma in 1968-1969 was associated with lower lung function values in 2000-2001, compared with non-asthmatics. In another study conducted between 1976 and 1994 including 17 506 subjects (9370 women), of whom 1095 had asthma, a greater decline in $\mathrm{FEV}_{1}$ over time was found among both male and female asthmatics as compared to non-asthmatics [10].

Self-reported mental stress and low socio-economic group in 1968-1969 were associated with airway symptoms in 2000-2001. These findings are in accordance with other studies on social class effects and health outcomes [11, 12].

We found that a high BMI $(>28)$ at baseline was related to self-reported obstructive symptoms $>30$ years later in this female population. These results are similar to those of Chen et al [13] who investigated the possibility of gender specificity in the BMI effect on the development of asthma. They used longitudinal data from the National Population Health Survey in Canada and 9149 subjects were included (4266 men and 4883 women). A high BMI was found to be a significant predictor of asthma incidence in women but not in men. The authors speculate that female sex hormones may play an important role in the aetiology of asthma and that these hormones are influenced by obesity. Direct effects of regurgitation due to abdominal obesity and inflammatory effects on the bronchioles have also been proposed as explanations of these associations. 
Experience of subsequent poor health was only associated to smoking, i.e. smoking seems to be the only factor except longstanding airway obstruction with a negative influence on a person's general health assessment. In women as well as men, low general health scores are potent predictors of mortality and morbidity [14].

\section{What is already known on this topic?}

There are a few previous longitudinal studies on obstructive and inflammatory lung diseases or COPD. A probability sample of the adult civilian population of the United States was followed for up to 22 years (1971-1992) in the first National Health and Nutrition Examination Survey. Subjects were classified according to a modification of the Global Initiative for Chronic Obstructive Lung Disease (GOLD) criteria for COPD. In this population study, 3034 female subjects were included and $1.2 \%$ was found to have severe and $6.2 \%$ had mild COPD. $16.1 \%$ had only respiratory symptoms at baseline. The survey showed that the presence of obstructive lung disease was a significant predictor of earlier death in long term follow-up. This was true for current and former smokers, but not for never-smokers [15].

A total of 13897 subjects from two population studies, The Copenhagen City Heart Study and the Glostrup Population Study, were followed for 7-16 years [16]. In the two independent population samples, smoking had greater impact on lung function in females than in males. After adjusting for smoking, females were subsequently at higher risk of admission to hospital for COPD. The results suggest that the adverse effects of smoking on lung function may be greater in females than in males. Similar results have been reported in other studies, indicating that females may be more susceptible than males to the deleterious effects of smoking with regard to pulmonary function and the development of COPD [17-19].

\section{Limitations and strengths of this study}

Problems with attrition are well known in longitudinal research, particularly as study populations reach advanced ages. Lissner et al [7] reported that the subjects who continue to participate in "The Prospective Population Study of Women in Gothenburg" are selected. However, the 32-year participation experience highlight the need to offer home visits to elderly subjects in order to obtain an acceptable participation rate as well as less selection bias. We have chosen to report from the youngest age cohort participating in "The Prospective Population Study of Women in Gothenburg" as this was the age group in which lung function status was most thoroughly examined and selection bias due to mortality and non-participation could be kept low, with a participation rate of $73 \%$ in the 32-year follow-up and with around $10 \%$ home visit examinations. The strengths of the study are the unusually high participation rate at baseline $(90 \%)$, the comprehensiveness of examinations and the access to national registers ensuring virtually complete follow-up even among subsequent drop-outs.

\section{What this study adds}

Over the past 50 years, a large number of prospective population studies have been initiated in different parts of the world, the Framingham Study being an early example [20]. As far as we know, there has been no other study of women with a combination of representative sampling, long follow-up, comprehensive examination protocols and high participation rates at baseline comparable to "The Prospective Population Study of Women in Gothenburg".

Smoking is associated with airway symptoms and is the most important causative agent for obstructive pulmonary disease, but there are only a few longitudinal studies concerning women's health problems in this field and epidemiological studies of lung function impairment in women and risk factors in a long-term perspective are scarce. The results of the study suggest that life-style factors such as mental stress, obesity and smoking among women are related to symptoms in the airway and also quality of life in a long-term perspective.

\section{Acknowledgements}

This study was funded by grants from the Swedish Research Council (345-2001-6652, 27X-04578, 2002-3724), the Bank of Sweden Tercentenary Foundation, and the Medical Faculty at the Sahlgrenska Academy at Göteborg University.

The Ethics Committee of Göteborg University approved the study. All subjects gave informed consent, in accordance with the provisions of the Helsinki Declaration.

\section{Conflict of Interests}

The authors have declared that no conflict of interest exists.

\section{References}

1. Lundbäck B, Lindberg A, Lindström $M$, et al. Not fifteen but fifty percent of smokers develop COPD - report from the Obstructive Lung Disease in Northern Sweden studies. Respir Med. 2003; 2: 115-22.

2. Persson C, Bengtsson C, Lapidus L, et al. Peak expiratory flow and risk of cardiovascular disease and death. Am J Epidemiol. 1986; 124: 942-8.

3. Bengtsson C, Blohmé G, Hallberg L, et al. The study of women in Göteborg 1968-1969 - a population study. General design, purpose and sampling results. Acta Med Scand. 1973; 193: 311-8.

4. Bengtsson C, Hallberg L, Hällström T, et al. The population study of women in Goteborg 1974-1975 - the second phase of a longitudinal study. General design, purpose and sampling results. Scand J Soc Med. 1978; 6: 49-54.

5. Bengtsson C, Gredmark T, Hallberg L, et al. The population study of women in Göteborg 1980-81 - the third phase of a longitudinal study. Comparison between participants and non-participants. Scand J Soc Med. 1989; 17: 141-5.

6. Bengtsson C, Ahlqwist M, Andersson K, et al. The Prospective Population Study of Women in Göteborg, Sweden, 1968-69 to 1992-93. A 24-year follow-up study with special reference to 
participation, representativeness, and mortality. Scand J Prim Health Care. 1997; 15: 214-9.

7. Lissner L, Skoog I, Andersson K, et al. Participation bias in longitudinal studies: experience from the Population Study of Women in Göteborg, Sweden. Scand J Prim Health Care. 2003; 21: 242-7.

8. Carlsson G. Social mobility and class structure. Lund, Sweden: CWK Gleerup; 1958.

9. Lange P, Parner J, Prescott E, et al. Chronic bronchitis in an elderly population. Age Ageing. 2003; 32: 636-42.

10. Lange P, Parner J, Vestbo J, et al. A 15-year follow-up study of ventilatory function in adults with asthma. N Engl J Med. 1998; 339:1194-1200.

11. Cabrera C, Helgesson Ö, Wedel H, et al. Socioeconomic Status and Mortality in Swedish Women: Opposing Trends for Cardiovascular Disease and Cancer. Epidemiology. 2001; 5: 532-6.

12. Helgesson Ö, Cabrera C, Lapidus L, et al. Self-reported stress levels predict subsequent breast cancer in a cohort of Swedish women. Eur J Cancer Prev. 2003; 12: 377-81.

13. Chen $Y$, Dales $R$, Tang $M$, et al. Obesity may increase the incidence of asthma in women but not in men: Longitudinal observations from the Canadian National Population Health Surveys. Am J Epidemiol. 2002; 155: 191-7.

14. Beny EL, Amini Y. Self-Rated Health and Mortality: A Review of Twenty-Seven Community Studies. J Health Soc Behav. 1997; 38: 21-37.

15. Mannino DM, Buist AS, Petty TL, et al. Lung function and mortality in the United States: data from the first National Health and Nutrition Examination Survey follow- up study. Thorax. 2003; 58: 388-93.

16. Prescott E, Bjerg AM, Andersen PK, et al. Gender difference in smoking effects on lung function and risk of hospitalization for COPD: results from a Danish longitudinal population study. Eur Respir J. 1997; 10: 822-7.

17. Xu X, Li B, Wang L. Gender difference in smoking effects on adult pulmonary function. Eur Respir J. 1994; 7: 477-83.

18. Xu X, Weiss ST, Rijcken B, et al. Smoking, changes in smoking habits, and rate of decline in $\mathrm{FEV}_{1}$ : new insight into gender differences. Eur Respir J. 1994; 7: 1056-61.

19. Chen Y, Home SL, Dosman JA. Increased susceptibility to lung dysfunction in female smokers. Am Rev Respir Dis. 1991; 143: 1224-30.

20. Kannel WB, Hubert H, Lew EA. Vital capacity as a predictor of cardiovascular disease: The Framingham Study. Am Heart J. 1983; 105: 311-5. 